\title{
Diálogos arriscados: do direito de participação cidadã na patrimonialização ao direito cidadão de aparecer no patrimônio cultural ${ }^{1}$
}

\section{Risky dialogues: from the right of citizen participation in patrimonialization to the right of citizens to appear in cultural heritage}

\author{
Diego Finder Machado²
}

\begin{abstract}
Resumo: Frente às demandas recentes por uma participação cidadã mais efetiva em políticas culturais, este artigo busca problematizar as relações entre profissionais e cidadãos comuns em processos de patrimonialização e nos usos e apropriações do patrimônio cultural. Parte-se das premissas de que a participação exige que um diálogo possa existir e de que esse diálogo sempre está sujeito a riscos: o risco de ser malentendido, o risco de ser entendido muito claramente e, ainda, o risco de desentendimentos entre as partes. Com base em exemplos de Joinville, Santa Catarina, são discutidos, primeiramente, os riscos de diálogos em situações de participação cidadã em atos de patrimonialização. Na sequência, sugere-se a ideia de que há algo que está para além da participação cidadã quando indivíduos e grupos profanam o patrimônio cultural e, nesse ato, reivindicam para si novos espaços de aparecimento na vida pública da cidade.
\end{abstract}

Palavras-chave: Patrimônio Cultural; Participação Cidadã, Espaços de Aparecimento.

\begin{abstract}
In consideration of recent demands for a more effective citizen participation in cultural policies, this article aims to discuss the relationships between experts and ordinary citizens in patrimonialization processes and in the uses and appropriations of the cultural heritage. It is based on the premises that participation requires that a dialogue can exist and that this dialogue is always a risk: the risk of being misunderstood, the risk of being understood much clearly and also the risk of divergent ideas between the actors involved in the patrimonialization process. Analyzing cases from Joinville, Santa Catarina, it debates, firstly, the risks of dialogues in situations of citizen participation in acts of patrimonialization. After that, it proposes the idea that there is something more than the citizen participation when individuals and groups profane the cultural heritage and, in this act, they are looking for new appearance spaces in the public life of the city.
\end{abstract}

Key words: Cultural Heritage; Citizen Participation, Appearance Spaces.

\section{Lugares (in)comuns: a "heterologia" do patrimônio}

Nas últimas décadas, demandas por uma participação cidadã mais efetiva em políticas de gestão do patrimônio cultural, inclusive nos processos de patrimonialização, têm ocorrido em diferentes escalas e contextos. Em âmbito local, ou ainda, em âmbitos nacional ou mundial, assume-se atualmente o princípio de que proteger, preservar e valorizar o patrimônio são ações que devem ser compartilhadas de forma abrangente e inclusiva na vida de uma sociedade. Com

\footnotetext{
${ }^{1}$ Uma versão preliminar deste texto foi apresentada na mesa redonda "Patrimônio Cultural e Participação Cidadã", durante a VII Jornada Catarinense de Estudos sobre o Patrimônio Cultural, promovida, em 3 de setembro de 2018, pelo Laboratório de Patrimônio Cultural da Universidade do Estado de Santa Catarina (LabPac/Udesc)

${ }^{2}$ Doutor em História. Bolsista do Programa Nacional de Pós-Doutorado da Coordenação de Aperfeiçoamento de Pessoal de Nível Superior (PNPD/Capes), vinculado ao Programa de Pós-Graduação em Patrimônio Cultural e Sociedade da Universidade da Região de Joinville (PPGPCS/Univille). Integra o Grupo de Pesquisa "Cidade Cultura e Diferença". E-mail: diego_finder@yahoo.com.br.
} 
isso, há o anseio por uma democratização do patrimônio em seus ritos de instituição e em seus usos e apropriações. Para tanto, os profissionais de diferentes áreas do saber relacionadas ao trabalho com o patrimônio, quando vinculados a órgãos públicos de preservação, são instados a agir em conjunto com os cidadãos comuns, ou seja, com públicos e usuários não especialistas.

No Brasil, a Constituição Federal de 1988, em seu Art. 216, significou uma importante virada, ao deslocar do Estado aos diferentes grupos formadores da sociedade a matriz de valores para o reconhecimento do patrimônio nacional (MENESES, 2012). Em certa medida, tal virada foi a conquista possível das reivindicações por maior participação e protagonismo social nas políticas públicas, reivindicações já invocadas no curso daquele processo constituinte (CAMPOS, 2018). Com a Emenda Constitucional n ${ }^{\circ} 71$ de 2012, que incluiu na Constituição o Art. 2016-A de modo a instituir o Sistema Nacional de Cultura, pode-se falar, ainda, de deslocamento da matriz de gestão do patrimônio cultural. Preconiza-se, desde então, a pactuação entre o poder público e a sociedade civil, de tal forma que os processos decisórios em relação às políticas culturais envolvam ampla participação e controle por parte dos cidadãos (RADUN, 2016). Essa realidade atual nos impulsiona à obrigação ética (e moral) de envolver a participação cidadã na patrimonialização de bens culturais. Mas isso, de fato, tem ocorrido na maioria das vezes? Ou, com muita frequência, trata-se apenas de um tipo de participação programada e controlada com a finalidade de transparecer uma imagem mais democrática?

Um dos slogans do Movimento de Maio de 68, acontecimento que abalou as estruturas da vida social na França da época, propunha uma conjugação alternativa e um tanto inusitada do verbo participar: Je participe, vous participez, il participe, nous participons, vous participez, ils profitent (Eu participo, tu participas, ele participa, nós participamos, vós participais, eles lucram). O slogan foi estampado em cartazes produzidos no Ateliê Popular, ocupação da Escola de Belas Artes por professores e alunos que durou pouco mais de um mês. A conjugação do verbo expressou uma crítica: ao passo que a maioria das pessoas "participa" da vida econômica, empregando sua força de trabalho, tão só uns poucos lucram com isso. No que diz respeito aos efeitos de uma política do patrimônio, caberia indagar: Quem lucra com a patrimonialização de bens culturais? Ainda que "participativa", os atos de patrimonialização podem ser mais do que um modo de concentrar lucros em mãos de poucos? Não me refiro apenas a lucros monetários, mas, principalmente, a possíveis lucros simbólicos. Quem pode acumular lucros em termos de “capital simbólico" com atos de patrimonialização? Utilizo aqui a categoria de Pierre Bourdieu (2004) para chamar a atenção para uma outra face do capitalismo, um capitalismo que controla a acumulação e distribuição de valores de ordem simbólica. Por mais que se considere que o 
ato de patrimonializar um bem cultural não é tão desinteressado a ponto de prescindir de capitais monetários, seja ao menos pelas expectativas de receber dividendos dos lucros advindos do incremento da indústria do turismo, geralmente se busca falar de valores simbólicos - portanto, valores incalculáveis e incomensuráveis - quando se fala de patrimônio cultural.

Os atos de patrimonialização de bens culturais implicam instituir e reforçar uma "ordem patrimonial", tanto no que diz respeito à organização espaço-temporal dos bens, de modo a evitar dispersões e confusões, como no que diz respeito à prescrição de usos admissíveis, com a finalidade de inibir gestos e relatos que afrontem ou confrontem a pretensa sacralidade do patrimônio (MACHADO, 2018a). Conforme Dominique Poulot (2009, p. 15), “o patrimônio elabora-se, em cada instante, com base na soma de seus objetos, na configuração de suas afinidades e na definição de seus horizontes". Os agentes incumbidos de gerir processos de patrimonialização esforçam-se, na maioria das vezes, para contemplar uma visão de conjunto, estabelecendo coesões e coerências para preencher as lacunas e ordenar, da melhor maneira possível, uma "comunidade" de bens aos quais se atribui algum valor e importância. Estima-se que se possa perceber afinidades implícitas na soma de bens culturais muito diversos e, ao primeiro olhar, descontínuos entre si, tanto no que se refere aos espaços que ocupam, como às temporalidades a que remetem. Com isso, há a expectativa de que as afinidades "reveladas" entre bens patrimonializados possam revelar, também, afinidades entre pessoas diferentes que integram "comunidades" às quais, pelo menos em teoria, as ações de proteção e preservação patrimonial são endereçadas. Logo, investe-se em práticas e saberes para estabelecer "lugares comuns", lugares que suscitem consensos e representem, a certos grupos, territórios e memórias comuns. Porém, a estranheza do patrimônio se instala na vida cotidiana e persiste nas maneiras díspares e imprevisíveis pelas quais os bens são recebidos pelos cidadãos e inseridos em suas relações de sociabilidades. Apesar dos esforços em direção oposta, o patrimônio cultural segue como um conjunto instável e disperso de "lugares incomuns", lugares sujeitos a gestos e relatos incongruentes e de contornos desmedidos.

A tarefa de preencher as lacunas que podem desestruturar a coesão e a coerência de uma “ordem patrimonial”, tarefa que cabe, em primeira instância, aos profissionais do patrimônio, envolve, por um lado, estabelecer uma topografia das narrativas sobre o passado, topografia de histórias ou de memórias, conforme a pretensão seja a de evocar conhecimentos sobre o passado ou reconhecimentos no passado. Assim, a diacronia do tempo pode se exprimir na sincronia de lugares a serem valorizados, protegidos e preservados. Por outro lado, preencher essas lacunas envolve, também, estabelecer estratigrafias temporais do espaço, ou seja, "escavar" camadas 
de temporalidades que se sobrepuseram a um lugar, em sua singularidade própria. Em suma, o ato patrimonializador se exprime na ambivalência de espacializar o tempo e de temporalizar o espaço. No que se refere especificamente ao patrimônio material, pode-se apontar dois distintos regimes de patrimonialização: o "regime de singularidade", que atribui valor a um bem cultural por sua excepcional raridade, e o "regime de comunidade", que atribui valor àquilo que está ligado a um conjunto cuja harmonia é depreendida da interação entre bens que, isolados, não teriam grande relevância (HEINICH, 2010-2011). A patrimonialização, primordialmente, é um trabalho técnico sustentado por práticas e saberes do campo interdisciplinar do patrimônio, da história à arquitetura, passando pela arqueologia, museologia, antropologia, dentre outras áreas do conhecimento. Porém é um trabalho que tem por objetivo envolver o cidadão comum, seja apenas no conhecimento e reconhecimento de valores previamente atribuídos, seja, ainda, em uma participação mais ativa nos processos de atribuição de valores patrimoniais e de gestão dos bens culturais patrimonializados.

Embora não se questione a relevância da participação dos cidadãos na patrimonialização de bens culturais, participação que oportuniza um maior protagonismo de pessoas diretamente envolvidas com o patrimônio, é preciso estar atento para um contrassenso. A patrimonialização, como insistiu Marc Guillaume (2003), é um artifício "heterológico". Trata-se de procedimento que cria alteridades: estabelece uma descontinuidade em relação a outros tempos e a outros no tempo, assim como uma separação ritual que torna extraordinário o que era tão somente um objeto ordinário. É o passado que passa a ser evocado por um bem cultural patrimonializado, por mais que se trate de um bem de uso ainda ativo no presente. Além do mais, por ter se tornado patrimônio, o bem passa a receber cuidados especiais que, em certa medida, retiram-no do "convívio" entre outros bens e separam-no, por zelo e prudência, da ordinariedade da vida social. Ocorre que ao reivindicar participação cidadã em processos de patrimonialização se está reivindicando, ao mesmo tempo, que haja, entre o cidadão e o "seu" patrimônio, continuidade e religação. Sem dúvida, isso é possível. Porém, já não se trata de reivindicar a posição de um usuário, mas, mais propriamente, a posição de usufrutuário do patrimônio. A este, cabe o dever de receber uma herança - a qual não é mais apenas um bem que lhe foi deixado para que pudesse se apossar livremente, mas um patrimônio que pertence a um todo social de limites imprecisos - para, no futuro, transmiti-la na mais plena integridade possível a outros usufrutuários.

A busca por estabelecer continuidades, apesar das descontinuidades, e por religar-se a algo do qual se está ritualmente separado, apenas seria tranquila em um contexto social em que fosse possível viver bem com as diferenças. Em uma situação ideal, a riqueza do patrimônio 
cultural, em termos simbólicos, seria justamente mostrar as alteridades e promover diálogos interculturais a partir de vestígios que indicam a presença de um outro ausente, em suas semelhanças e diferenças em relação a nós. Todavia, a procura narcisista por um reflexo de si nas marcas do passado que ainda perduram dificulta o estabelecimento de continuidades temporais entre as diferenças e entre os diferentes, assim como cria obstáculos para que haja a religação do extraordinário do patrimônio com o ordinário do cotidiano vivido pelos cidadãos. De acordo com Marc Guillaume (2003, p. 124-125), há um paradoxo na política do patrimônio: “ela esforça-se por pôr em cena uma continuidade com o passado, quando a conservação é precisamente o local de uma ruptura radical com ele, ruptura que ela está, pois, condenada a dissimular perpetuamente".

Neste artigo, proponho um modo de pensar a respeito das relações, frequentemente tensas e conflituosas, entre profissionais e cidadãos comuns quando interagem na vida social com e no patrimônio cultural. Os exemplos analisados referem-se a atos de patrimonialização que ocorreram na cidade de Joinville, Santa Catarina, a partir da segunda metade do século XX. Portanto, a temática abordada tem como pano de fundo o lugar do patrimônio em cidades contemporâneas, cidades que vivenciam a ambivalência entre a efemeridade do consumo e a persistência da conservação. Em um primeiro momento, são problematizados os riscos do diálogo intercultural nas situações de participação cidadã em atos de patrimonialização. Na sequência, sugiro a ideia de que há algo que está para além da participação cidadã quando indivíduos e grupos "profanam" o patrimônio cultural e, nesse ato, reivindicam para si novos "espaços de aparecimento" na vida pública da cidade. Buscarei, então, responder, ainda que provisoriamente, a uma questão: Para além da participação cidadã relativamente controlada, é possível a qualquer pessoa acumular lucros simbólicos em atos de patrimonialização de bens culturais? Ou seja, há, aos que estão de fora de rituais participativos, algum quinhão a receber?

\section{Arriscar-se no diálogo com o outro: as disputas pelo "participável” do patrimônio}

Propor uma participação exige, de saída, que um diálogo possa existir, diálogo entre partes dispostas a negociar suas diferenças em prol de algo que possa ser visto como comum a ambas. Em jogo nesse diálogo está o "participável”, ou seja, aquilo que foi posto em discussão. Há que se reconhecer, nesse sentido, que não é todo e qualquer assunto que pode ser submetido à participação. A própria palavra "participar", do latim participare, significa "receber algo de outrem", levando em conta que o que é recebido não o é em sua totalidade (SANTOS, s/d). Um 
participante só pode participar do participável e quem define o conteúdo participável define, também, as regras da participação. Portanto, reivindicações por participação cidadã se deparam, inevitavelmente, com as limitações do participável e com as limitações da cidadania.

Isso é evidente em processos de patrimonialização, cujos limites do participável são bem demarcados. Costuma-se dizer que há deliberações em relação ao patrimônio que precisam ser tomadas em conjunto com os cidadãos comuns, de modo abrangente, enquanto outras devem ficar restritas ao que pensam e dizem os profissionais da área. Muitas vezes, diálogos somente se mostram possíveis quando há alguma equivalência, no que tange a saberes e poderes, entre os profissionais que atuam nos órgãos de gestão do patrimônio e os cidadãos convidados a participar. Daí uma busca pela colaboração de experts de diferentes áreas do saber que atuam em universidades ou em associações profissionais. É, por assim dizer, uma participação cidadã por delegação. Agentes bem posicionados no campo do patrimônio, assim como as instituições que eles representam, ocupam lugares privilegiados em conselhos e comissões com poderes consultivos e deliberativos. A tais agentes é delegado um poder de decisão para ativar certos patrimônios, com o compromisso de representar os interesses e anseios de uma coletividade difusa. Algumas decisões quanto à gestão de uma política do patrimônio, pela complexidade e impacto na vida social, precisam ser avalizadas por instâncias consultivas e deliberativas que envolvem, em diálogos democráticos, a participação da sociedade civil. Certamente, o diálogo em tais instâncias pode frustrar as expectativas de técnicos e gestores públicos, os quais, por vezes, buscam apenas ter suas decisões corroboradas. Porém, é necessário estar atento ao fato de que, quando o diálogo é oportunizado no campo da gestão pública do patrimônio, há esforços para delimitar o participável e, de certo modo, para ditar o curso da participação.

Na cidade de Joinville, a participação cidadã em processos de patrimonialização de bens materiais e imateriais, no âmbito municipal, se dá, basicamente, por representantes da sociedade civil que integram a Comissão do Patrimônio Histórico, Arqueológico, Artístico e Natural do Município (COMPHAAN). Instituída pela Lei $\mathrm{n}^{\circ}$ 1.772, de 18 de novembro de 1980, compete a essa comissão tomar decisões a respeito das políticas municipais de gestão do patrimônio na cidade (JOINVILLE, 1980a), notadamente em processos de tombamento, de acordo com a Lei $\mathrm{n}^{\circ} 1.773$, de $1^{\circ}$ de dezembro de 1980 (JOINVILLE, 1980b), e de inventário, de acordo com a Lei Complementar no 363, de 19 de dezembro de 2011 (JOINVILLE, 2011). Atualmente, essa comissão é composta por dezoito membros, dos quais a metade representa o poder executivo municipal, ao passo que a outra metade representa a sociedade civil, incluindo profissionais do 
meio acadêmico e de associações profissionais ${ }^{3}$. Trata-se, sem dúvida, de uma participação institucionalizada e programada, que permite a abertura de um debate dominado apenas por profissionais de diferentes especialidades, sejam ou não eles servidores públicos. Não obstante, como as decisões são tomadas em colegiado, busca-se transmitir a impressão de que o mapa do patrimônio de Joinville costuma ser demarcado de maneira participativa e democrática.

Referindo-se à composição do Conselho Consultivo do órgão federal de preservação, o atual Instituto do Patrimônio Histórico e Artístico Nacional (IPHAN), Denis Radun (2016, p. 144) concluiu que "a participação cidadã é controlada e filtrada pelo conhecimento autorizado e pelas relações políticas", já que a sociedade civil é tão somente representada por membros indicados. Porém, face a uma "nova matriz de gestão do patrimônio cultural”, instituída no Art. 216-A da Constituição Federal de 1988, caberia promover a democratização dos processos decisórios relacionados à patrimonialização e, também, à “despatrimonialização". Para ele, "o ingresso de novos atores nas instâncias decisórias" poderia ampliar o "rol daqueles que possuem legitimidade e autoridade para dizer o que é patrimônio cultural", desestabilizando "as posições cativas do campo, aquelas de profissionais e órgãos a ele reconhecidamente afetos" (RADUN, 2016, p. 152). A exemplo do que ocorre na gestão do meio-ambiente, o autor sugeriu que a gestão pública do patrimônio cultural poderia se valer de determinados instrumentos jurídicos com vistas a democratizar suas ações, ao promover audiências e consultas públicas, assim como ao elaborar, em diálogo com as partes envolvidas, planos de manejo. Logo, uma nova matriz de gestão do patrimônio exigiria a criação de novos e mais abertos espaços de diálogo, assim como a amplificação das vozes dos cidadãos em deliberações quanto ao presente e ao futuro de bens culturais com os quais convivem em seu cotidiano.

Parto de uma premissa suscitada por Arjun Appadurai (2009, p. 23), segundo a qual “ninguém pode envolver-se num diálogo sem correr sérios riscos". A questão levantada pelo autor foi a seguinte: Por que vale a pena, ou é forçoso, correr tais riscos? Na visão dele, riscos em diálogos podem ser de dois tipos: o risco de ser mal-entendido e, do lodo oposto, o risco de ser entendido muito claramente. Há um paradoxo posto aqui, pois se mostra tão arriscado ser compreendido quanto o é ser incompreendido pela outra parte no diálogo. Inclusive, para Appadurai a compreensão demasiada é o maior risco que corremos ao dialogar com os outros.

\footnotetext{
${ }^{3}$ Atualmente, a COMPHAAN é composta por seis representantes da Secretaria de Turismo e Cultura, um da Secretaria de Planejamento Urbano e Desenvolvimento Sustentável e dois da Secretaria do Meio Ambiente. Em relação à sociedade civil, as seguintes entidades contam com um representante: Centro de Defesa dos Direitos Humanos, Centro do Engenheiros e Arquitetos de Joinville, Conselho Municipal de Política Cultural, Conselho Regional de Engenharia, Arquitetura e Agronomia, Curso de Arquitetura da Sociedade Educacional de Santa Catarina, Curso de História da Universidade da Região de Joinville, Instituto de Arquitetos do Brasil, Ordem dos Advogados do Brasil e Sindicato da Indústria da Construção Civil de Joinville.
} 
A gestão do patrimônio cultural, que se sustenta em saberes e práticas relativamente esotéricos à maior parte das pessoas, presta-se, muito facilmente, a mal-entendidos. É difícil ao cidadão comum entender a linguagem cifrada das disciplinas do patrimônio e, ainda mais, o ritual que transubstancia um objeto comum em um patrimônio cultural que deve ser protegido, preservado e valorizado. Ainda que busquem se fazer claros, frequentemente os profissionais do patrimônio encontram dificuldades para dialogar com públicos e usuários não especialistas.

Um caso anedótico na história da criação de uma política do patrimônio em Joinville pode elucidar o risco de ser mal-entendido. Em 1982, o tombamento municipal de um conjunto de palmeiras imperiais da Alameda Brüstlein foi tema que ocupou páginas dos jornais locais em Joinville. Esse seria o primeiro tombamento municipal na cidade, ato que, pouco depois, acabou esquecido e desconsiderado ${ }^{4}$. Na época, a palavra "tombamento", por sua polissemia, estava sujeita a mal-entendidos. Embora já houvesse na cidade três bens tombados em nível federal $^{5}$, a maioria da população desconhecia o significado da palavra tombamento, pelo menos como ato de proteção patrimonial. Uma nota, publicada no jornal A Notícia, narrou o diálogo de um repórter e um fotógrafo com o subgerente da agência bancária localizada nas adjacências da Alameda Brüstlein. Em busca do melhor ângulo para uma fotografia, o repórter e o fotógrafo solicitaram acesso ao alto do prédio da agência. Ao recebê-los, o subgerente teria indagado: "Este tombamento das palmeiras não poderá causar acidente? E se as palmeiras caírem sobre as casas?" Ao fim, a nota dizia que os profissionais do jornal "tombaram, ali mesmo, diante do visual das centenárias e imperiais palmeiras" (O TOMBAMENTO, 1982, p. 2).

Mal-entendido semelhante foi satirizado em uma charge de Carlos Horn, publicada no jornal A Notícia. Na charge, os profissionais do patrimônio, segurando papéis que compõem a burocracia do ato preservacionista e a fita métrica que serviria para delimitar a abrangência do espaço a proteger, foram surpreendidos por uma pessoa disposta a participar do tombamento. Imaginando-se precavido, o colaborador trazia uma ferramenta para "tombar" as palmeiras: um machado. A fala da personagem não deixou dúvidas quanto ao seu intento: "Tô chegando prá participar do ‘tombamento' da tal Rua das Palmeiras!” (HORN, 1982, p. 2). Em pânico com a ajuda oferecida, os profissionais foram caricaturados boquiabertos e com cabelos em pé. Afinal, o que a uns poderia ser interpretado como ferramenta útil, a outros era uma arma ameaçadora. A charge representava, com humor, uma falha na comunicação entre profissionais e um cidadão

\footnotetext{
${ }^{4}$ O Livro Tombo que registrou o tombamento da Alameda Brüstlein em 1982 foi perdido. Somente em 9 de março de 2005, a alameda teve o seu tombamento oficializado pelo Decreto Municipal no 12.276 (JOINVILLE, 2005a). ${ }^{5}$ Até 1996, o munícipio contava com apenas três bens tombados na esfera federal: o "Palácio dos Príncipes" (atual sede do Museu Nacional de Imigração e Colonização), o Cemitério Protestante (conhecido como Cemitério do Imigrante) e um bosque que pertenceu ao orquidófilo Adalberto Schmalz.
} 
comum, um mal-entendido causado por significados distintos atribuídos à palavra tombamento, na dubiedade entre preservação e destruição. Obviamente, o exemplo expressa um caso limite e exagerado de incompreensão. Porém, sinaliza que a busca por consensos em uma política de patrimônio pode se deparar com uma série de dificuldades, inclusive de ordem semântica.

Levando em conta que um entendimento nunca pode ser absoluto, já que os processos de significação são contingentes e dependem de um contexto específico de interlocução, aquilo que, em determinado momento, é tido como um mal-entendido só pode ser considerado assim de modo relativo. Portanto, o entendimento é sujeito a disputas pela consolidação de um regime de verdade. Uma "ordem patrimonial" é atravessada por práticas discursivas de disciplinas que definem e redefinem, em suas interações interdisciplinares, os limites daquilo que se pode dizer sobre a "verdade" do patrimônio. Tais disciplinas, conforme Michel Foucault (1996, p. 8-9), funcionam em uma "ordem do discurso", já que "a produção do discurso é ao mesmo tempo controlada, selecionada, organizada e redistribuída por certo número de procedimentos que têm por função conjurar seus poderes e perigos, dominar seu acontecimento aleatório, esquivar sua pesada e temível materialidade". Em nossa sociedade, a circulação e a apropriação de discursos se dá por relações assimétricas e difusas de saber e de poder, pelas quais alguns procedimentos de exclusão entram em jogo para interditar ou segregar o poder de falar. Tais relações se valem de vontades de verdade apoiadas em suportes institucionais que exercem poder de coerção na distribuição de discursos. $\mathrm{O}$ que se considera um discurso verdadeiro não passa de uma vontade de verdade que encontra respaldo institucional, ou seja, a vontade de verdade que é capaz de se situar "no verdadeiro" de uma disciplina. Assim, conclui-se que uma verdade é uma convenção historicamente constituída, convenção que mascara sua origem em desejos e poderes. Segundo Foucault (1996, p. 20), nós ignoramos "a vontade de verdade, como prodigiosa maquinaria destinada a excluir todos aqueles que, ponto por ponto, em nossa história, procuraram contornar essa vontade de verdade e recolocá-la em questão contra a verdade".

Uma "verdade" sobre o patrimônio é elaborada, em meio a diálogos e debates, por meio de falas de autoridade que se exprimem nos discursos de determinados profissionais. Ainda em relação ao processo que culminou no tombamento da Alameda Brüstlein em 1982 por decisão da COMPHAAN, pareceres de especialistas serviram de embasamento para definir os valores simbólicos do conjunto de palmeiras imperiais. Três membros daquela comissão apresentaram argumentos favoráveis ao tombamento: o ambientalista Lenin Peña e os historiadores Adolfo 
Bernardo Schneider e Elly Herkenhoff ${ }^{6}$. O que me pareceu curioso ao investigar esse processo, foi o argumento utilizado pelos historiadores em seus esforços interpretativos para indicar qual teria sido a destinação do bem cultural, ao vincular o plantio das palmeiras a um gosto peculiar do príncipe francês François Ferdinand Philippe, o "Príncipe de Joinville".

Em 1843, o Príncipe de Joinville recebeu como dote pelo seu casamento com a princesa brasileira Francisca Carolina uma porção de terras localizadas na região nordeste da província de Santa Catarina. Após dificuldades financeiras com o fim da monarquia na França, em 1848, parte do dote foi vendida à Companhia Colonizadora de Hamburgo que passou a transportar imigrantes alemães e suíços para fundar a então Colônia Dona Francisca. Os príncipes, embora lembrados nas narrativas sobre o momento fundante da cidade de Joinville, nunca pisaram nas terras originadas do dote matrimonial, tampouco manifestaram esse desejo (FICKER, 2008).

Em 1838, ao aportar pela primeira vez no litoral do Rio de Janeiro, o príncipe registrou em seu Diário de Viagem o encantamento pela vegetação brasileira, apontando sua predileção: "Partout le cocotier, mon arbre favori!" (Por todos os lados havia coqueiros, minha árvore preferida) ${ }^{7}$. Segundo Adolfo Bernardo Schneider e Elly Herkenhoff, o gosto do príncipe era extensivo à palmeira, planta da mesma família botânica e esteticamente semelhante. Isso teria motivado a preparação de um cenário com a intenção de convencer o príncipe a se estabelecer na Colônia Dona Francisca, oferecendo-lhe uma dupla fileira de palmeiras imperiais originadas de sementes do Jardim Botânico do Rio de Janeiro. Como escreveu Adolfo Bernardo Schneider (1982), “o Príncipe de Joinville adorava as palmeiras, que classificou entre os vegetais mais bem feitos pelo Criador" e, por isso, algumas pessoas se encarregaram do plantio de duas aleias, já que "queriam que o príncipe, caso resolvesse fixar residência em Joinville, desde o primeiro momento se sentisse em casa". Elly Herkenhoff (1987, p. 170), por sua vez, afirmou que "o Príncipe de Joinville sempre foi um apaixonado das palmeiras, tanto é que, ao chegar pela primeira vez ao Brasil, em 1838, fez a seguinte exclamação: 'Portout le cocotier, mon arbre favori!'”. A interpretação da anotação do príncipe deduzia, facilmente, que ele era apaixonado por palmeiras, ainda que tenha dito que o coqueiro era a sua árvore favorita.

Ao buscar preencher lacunas do passado e elaborar alguma coerência narrativa de modo a sustentar o valor simbólico e patrimonial da Alameda Brüstlein, Adolfo Bernardo Schneider

\footnotetext{
${ }^{6}$ Os pareceres de Lenin Peña e Adolfo Bernardo Schneider constam no arquivo na Coordenação de Patrimônio Cultural da Secretaria de Cultura e Turismo de Joinville. Embora não tenha sido localizado o manuscrito do parecer de Elly Herkenhoff, o mesmo foi incluído por ela no livro Era uma vez um simples caminho..., publicado em 1987. ${ }^{7}$ No dia $1^{\circ}$ de janeiro de 1838 , o príncipe anotou no Diário de Viagem suas impressões sobre o momento em que aportou na Baía de Guanabara: "Começo por desejar feliz ano-novo a todo mundo. Nós costeamos ao longo de belos trechos bem arborizados, com essa vegetação equatorial tão rica e tão variada; por todos os lados havia coqueiros, minha árvore preferida” (D’ORLÉANS, 2006. p. 20).
} 
e Elly Herkenhoff se fiaram na presumida "nobreza" de um lugar originado do gosto peculiar do príncipe francês. Duas décadas antes, outro historiador já havia apontado o mal-entendido dessa interpretação forçada do passado de Joinville. Em 1961, Carlos Ficker, então presidente da Comissão do Museu Nacional de Imigração e Colonização, em uma série de textos para o jornal A Notícia chamou a atenção para o fato de que cocotier, palavra usada pelo príncipe, significa coqueiro em português, e não palmeira, cuja palavra correta em francês seria palmier. Segundo ele, uma interpretação atenta da documentação dava "a impressão de que o príncipe de Joinville apesar do seu amor pelos coqueiros, manifestado em 1838, não transformou seu velho sonho em realidade". Afinal, o príncipe "residia em Claremont e Neuilly e de certo pouco se interessava com a plantação de algumas palmeiras no seu terreno em Joinville”. Mencionou, contudo, que não queria "desiludir as almas românticas e os historiadores convencidos, que graças ao verdadeiro amor do Príncipe pelos 'COCOTIERS', Joinville hoje pode apresentar um castelo no final de uma longa e bonita alameda de palmeiras" (FICKER, 1961).

É interessante notar que a Alameda Brüstlein foi enobrecida pela patrimonialização. Tal "enobrecimento" refere-se ao modo como a presença ausente do príncipe foi constantemente reiterada no delineamento do valor atribuído ao bem. Muitas narrativas históricas partem de um momento mítico inaugural no qual tudo teria começado com um príncipe, uma princesa e um dote de casamento. Assim, a alameda de palmeiras imperiais compôs o cenário de uma história que vincula o "nascimento" da cidade a uma origem nobre. Por outro lado, esse caso demonstra, também, a autoridade das falas dos historiadores para sustentar o tombamento. Poucos, naquela situação, ousariam afrontar tal autoridade e contestar a força de verdade das interpretações sobre o passado da cidade e, em particular, sobre a destinação história da Alameda Brüstlein. Ainda que Adolfo Bernardo Schneider e Elly Herkenhoff não fossem historiadores de formação, mas amadores da pesquisa histórica, eram reconhecidos publicamente com a autoridade disciplinar.

Recentemente, na minha pesquisa de doutorado (MACHADO, 2018a), pude observar a evocação de autoridades disciplinares em falas de profissionais que trabalham com o patrimônio em Joinville. Nessas falas, é possível perceber a luta constante contra as perdas em relação a uma "comunidade" de bens culturais, perdas que, para eles, são causadas, na maior parte das vezes, por “incompreensão”. Essa é uma das faces retóricas de uma política do patrimônio, uma "retórica da perda" (GONÇALVES, 2002). Em duas entrevistas orais, notei uma vontade, no trabalho com o patrimônio, de minimizar o risco de um entendimento equivocado por parte dos cidadãos comuns no que se refere à importância do patrimônio cultural da cidade. 
A restauradora Gessonia Leite de Andrade Carrasco (2016) explicou que a área em que ela atua tem por desafio estender ao máximo a vida das coisas do passado ${ }^{8}$. Trata-se, entretanto, de medicina inconveniente, pois, como ela disse, o ideal seria não intervir em bens materiais protegidos: "O que eu queria mesmo é que a gente não precisasse mais restaurar coisas, que a gente só tivesse que cuidar delas para que vivessem mais tempo, assim como o médico cuidaria do ser humano para que ele vivesse mais tempo e não tivesse que fazer intervenções cirúrgicas". Abdicar de uma atitude invasiva, ou seja, abdicar de restaurar coisas e priorizar a conservação, exigiria o reconhecimento disseminado da importância do patrimônio. Essa não era, ao ver dela, a realidade brasileira, pois "as pessoas não respeitam o patrimônio, não entendem, acham que é coisa velha, que pode acabar”. Para ela, caberia aos gestores e profissionais do patrimônio ouvir as pessoas: "Eu não vejo como você tombar um bem sem você perguntar para as pessoas que vivem nessa cidade se elas querem isso ou não".

Para a historiadora Dietlinde Clara Rothert (2010), as políticas públicas de patrimônio em Joinville sempre se depararam com a dificuldade de promover maior "conscientização" da população". Como disse: "Quando a gente vê que consegue conversar mais com as pessoas, que elas têm um pouco mais de entendimento do que é o tombamento, eu acho que elas acabam aceitando melhor". Acredita que foi a falta de conhecimento que motivou perdas em relação ao conjunto patrimonial da cidade. Inclusive, como destacou, essa destruição teria ocorrido com o objetivo de valorizar uma certa ideia de "cidade germânica", já que antigos casarões da região central foram destruídos para ceder espaço a edificações que imitam a arquitetura do passado: "Demoliram coisas muito mais ricas e colocaram um falso histórico ali. Então, isso foi uma pena. Falta de conhecimento mesmo. Por que se as pessoas tivessem preservado aquilo que elas tinham, hoje o centro da cidade seria um cartão postal". Admitiu, todavia, que não adiantava investir tantos esforços se a própria população não pudesse entender a preservação como algo que lhe diz respeito. Para ela, haveria de se questionar: "Qual é a vontade da população?” Ao rememorar a própria trajetória, ela manifestou mudança de ênfase: "Eu já tive a fase de achar que tem que preservar tudo. Depois de tantos anos eu já paro para me perguntar e penso assim: Será que o povo quer isso mesmo? O que o povo quer? Vamos perguntar o que o povo quer".

\footnotetext{
${ }^{8}$ Natural de Ortigueira, no estado do Paraná, Gessonia Leite de Andrade Carrasco atuou no órgão de cultura do munício de Joinville entre os anos de 1984 e 2018. Além do trabalho como restauradora do Centro de Preservação de Bens Culturais, assumiu, por períodos curtos, os cargos de coordenadora da Estação da Memória, coordenadora do Arquivo Histórico de Joinville e gerente de Patrimônio, Ensino e Arte.

${ }^{9}$ Natural de Joinville, Dietlinde Clara Rothert é uma das servidoras mais antigas do órgão de cultura do munício, onde atua desde 1982. Atualmente, é responsável por organizar e disponibilizar os documentos relacionados aos processos de tombamento e de inventário junto à Coordenação de Patrimônio Cultural.
} 
É preciso levar em conta que a defesa do patrimônio é um trabalho que exige, a todo instante, estratégias de convencimento. Talvez tais estratégias se mostrassem mais eficazes se envolvessem, de alguma forma, o cidadão comum nos processos de patrimonialização. Para tanto, seria necessário um diálogo que não viria, com atraso e de maneira paliativa, a atuar tão só no reconhecimento de valores previamente definidos por agentes investidos de autoridade. Paulo Peixoto (2016) falou em "tirania da participação cidadã”, expressão antitética que chama a atenção para um impasse nas atuais políticas patrimoniais. De acordo com ele, "tombamento, preservação, salvaguarda, gestão, ou qualquer prática de valorização estão condicionadas ao imperativo da participação", o que, como ele argumentou, "é um dos maiores demônios atuais do patrimônio" (PEIXOTO, 2016, p. 290). Duas constatações em relação a isso: o campo do patrimônio é dominado pela lógica da profissionalização e, decorrente disso, acaba por ficar à margem das urgências e prioridades de indivíduos e grupos. Embora busque abarcar "todas as dimensões da vida e das práticas sociais", o conceito de patrimônio cultural acabou "fechandose progressivamente em uma linguagem técnica e hermética" (PEIXOTO, 2016, p. 290). Em geral, as políticas patrimoniais escapam das preocupações imediatas de indivíduos e grupos. A participação cidadã, ainda que invocada em atos de patrimonialização, dificilmente é mais do que uma mera participação institucionalizada e programada.

Para Gessonia Leite de Andrade Carrasco e Dietlinde Clara Rothert, seria necessário perguntar à população da cidade o que, de fato, ela gostaria de preservar. Contudo, a resposta a essa pergunta poderia se restringir a um constrangedor silêncio. Há uma distância abismal entre as aspirações do cidadão comum e a lógica de funcionamento do campo patrimonial. Por mais que haja a vontade de disseminar conhecimentos sobre o patrimônio, educando a população da cidade para reconhecer os "seus" bens e para se reconhecerem em sua historicidade, a lógica da patrimonialização continua esotérica e estranha à maioria das pessoas.

Volto-me agora ao segundo risco evocado por Arjun Appadurai (2009): o risco de ser compreendido com muita clareza em diálogos interculturais. Isso parece bastante paradoxal e, conforme o autor, "este paradoxo assenta em parte na preocupação de que o outro possa ver para lá das expressões superficiais e entenda motivos ou intenções que preferimos ocultar". Para ele, "isto é um risco porque o diálogo não diz respeito a tudo. Para que seja um diálogo eficaz terá de se basear, até certo ponto, em terreno comum, concordância seletiva e consenso conjuntural" (APPADURAI, 2009, p. 24). Obviamente, é impossível que um diálogo permita a compreensão mútua na sua plenitude. Afinal, anseios, desejos e visões de mundo diferentes são evocados pelas partes em diálogo. No entanto, a tentativa de atingir a plenitude na compreensão 
pode levar ao impulso de anular diferenças fundamentais. Ainda para o autor, "todo o diálogo é uma forma de negociação e a negociação não pode basear-se numa compreensão mútua completa ou num consenso total que atravesse qualquer espécie de fronteira de diferenciação" (APPADURAI, 2009, p. 25). O risco é o de que uma das partes, a mais forte, arrogue-se da capacidade de saber o que é melhor para a outra, com tamanha convicção a ponto de anular o que ela pensa sobre si e deseja para si.

Em relação a esse risco de plena compreensão, narro brevemente o caso de uma ponte que, ao invés de travessia, tornou-se um impasse na vida dos moradores de um bairro na área rural de Joinville. Em 24 de fevereiro de 2016, alguns representantes da Prefeitura de Joinville, incluindo técnicos e gestores do órgão de cultura, participaram de uma reunião chamada pela diretoria da Associação de Moradores das Estradas do Sul e Blumenau, do bairro Vila Nova. $\mathrm{Na}$ condição de pesquisador, eu acompanhei presencialmente a realização dessa reunião. Os moradores do bairro reivindicavam o "destombamento" da ponte coberta da Estrada Blumenau, bem protegido por tombamento em âmbito municipal, e exigiam da Prefeitura de Joinville a imediata construção de uma nova ponte de concreto, mais moderna e segura para a passagem de veículos e máquinas agrícolas de grande porte. Dentre os argumentos dos moradores locais, dizia-se que a ponte, por ser coberta, costumava servir de abrigo a "vândalos" e "baderneiros". Ao usufruírem do rio para o seu lazer, algumas pessoas perturbavam o sossego dos residentes.

Como se pode imaginar, os técnicos e gestores do órgão de cultura não foram para essa a reunião dispostos a ceder às pressões e colocar em questão o ato de tombamento. Já de início, o controle da reunião mudou de mãos, pois um possível cancelamento do tombamento da ponte não poderia, na visão dos profissionais, ser um ponto de pauta “participável”. Essa não era uma decisão que caberia unicamente aos moradores locais, tampouco aos técnicos lá presentes, já que o tombamento havia consagrado um valor simbólico de interesse difuso, de todas as pessoas que vivem em Joinville. Havia, então, uma fronteira invisível entre as partes em diálogo. Por esse motivo, os técnicos e gestores se colocaram na tarefa de convencer os moradores locais de que a ponte era uma bem comum a todos e de que, por isso, era boa para a vida de todos eles.

A ponte possui uma trajetória inusitada, com momentos de "morte" e "ressurreição". Construída em 1866, por um engenheiro alemão, apenas cinco anos depois foi completamente destruída em uma enchente. Logo no ano seguinte, foi reconstruída pelo trabalho de moradores da localidade. Já no século XX, em 1936, a ponte foi reformada pela Prefeitura de Joinville, mantendo aspectos presumidamente originais. Em 2008, a ponte foi novamente destruída por conta de chuvas torrenciais na região e, logo depois, reconstruída. A última catástrofe, em 2015, 
ocorreu após um vendaval que arrancou a cobertura. Na ocasião, moradores recorreram a órgãos públicos para pedir que aquela ponte não fosse mais reconstruída e desse lugar a outra, mais moderna (FCJ, 2005b). Possivelmente, se há algo de "autêntico" em termos patrimoniais na história da ponte não é, propriamente, a sua materialidade, mas a sua imaterialidade, ou seja, a transmissão de um "saber-fazer” mobilizado para reconstruí-la após cada catástrofe.

Desde 2005, a ponte coberta da Estrada Blumenau é um bem cultural tombado pela municipalidade. Na época, conforme o Decreto $\mathrm{n}^{\mathrm{o}} 12.591$, de 10 de setembro de 2005, a ponte foi considerada "uma das principais obras arquitetônicas dos imigrantes europeus do Bairro Vila Nova", além de "um marco histórico que precisa ser preservado porque sobre ela muita riqueza foi transportada simbolizando assim a força de seus desbravadores” (JOINVILLE, 2005). O argumento utilizado para decidir pelo tombamento era o de que a população desejava a proteção daquele bem. A suposição pautou-se em um documento de 1993, pelo qual Arinor Vogelsanger, um vereador que morava no bairro, solicitou o tombamento da ponte. Contudo, já naquela época ele havia salientado que, "além do merecido tombamento", os moradores reivindicavam a sua reconstrução "nos moldes originais", bem como "a construção de outra ponte (de concreto), nas proximidades, para atender as necessidades atuais da região" (VOGELSANGER, 1993). Ao mencionar a vontade de uma pessoa do bairro já falecida, empresário e político que exerceu e ainda exerce entre alguns dos moradores um papel de referência simbólica na história daquela região de Joinville, os ânimos se acalmaram. Ao fim da reunião, ficou acordado que não se falaria mais no destombamento da ponte. Os moradores foram, de certo modo, "convencidos" do valor do patrimônio. Porém a reivindicação por uma nova ponte não esmoreceu ali. Foi cobrado do poder público o cumprimento da promessa de resolver o impasse que aflige a vida dos moradores do bairro.

O desenlace do caso da ponte coberta da Estrada Blumenau sinaliza outra face retórica de uma política do patrimônio: uma retórica moral. Segundo Nicolas Adell (2016), houve, na virada do século XX para o XXI, uma "inversão patrimonial” no que se refere às políticas de proteção e preservação. Essa inversão se deu por uma "guinada espacial", ao deixar de valorizar tão somente bens singulares e isolados para dar importância a territórios e conjuntos, e uma "guinada moral", ao tender a valorizar uma postura "reflexiva" ou "especular" em relação ao patrimônio. Passou-se de uma moral muito fechada, uma moral "cívica", a uma moral aberta, “que se baseia menos na coerção do que na atração, no fato de suscitar uma adesão e de criar movimento para obedecer aos princípios não fixados em instituições, mas incorporados pelos indivíduos" (ADELL, 2016, p. 34). Essa moral aposta na aderência voluntária de comunidades 
no envolvimento com o patrimônio que supostamente lhes pertence. Julga-se, desse modo, que “o patrimônio e a patrimonialização se abrem para o 'Bem' das comunidades envolvidas, pois implicadas em todas as fases da operação patrimonial, elas não saberiam jogar contra elas próprias" (ADELL, 206, p. 37). Ora, isso é, sem dúvida, um jogo retórico. O patrimônio, mais do que "lugar comum", persiste como lugar estranho e incomum na vida das pessoas, pois os valores simbólicos extraordinários atribuídos ao patrimônio costumam estar muito distantes dos interesses mundanos dos cidadãos comuns. Contudo, essa estranheza pode ser bastante fecunda, no que se refere aos usos e apropriações do patrimônio e às narrativas sobre seus significados simbólicos. Por ser incomum, o patrimônio suscita gestos e relatos que podem provocar fissuras na retórica moral que prediz, com uma certeza arrogante, o que deve ser bom para todos.

\section{Desentendimentos: profanar o patrimônio e reivindicar espaços de aparecimento}

Aos já mencionados riscos que corremos em um diálogo, ou seja, os riscos de ser malentendido ou de ser entendido muito claramente, acrescento outro: o risco de desentendimentos entre interlocutores que buscam, no diálogo, chegar a algum acordo. Segundo Jacques Rancière (1996, p. 11), o desentendimento é um tipo particular de situação do diálogo: "aquela em que um dos interlocutores ao mesmo tempo entende e não entende o que diz o outro". Para o autor, "o desentendimento não é o conflito entre aquele que diz branco e aquele que diz preto", mas, ao contrário, "é o conflito entre aquele que diz branco e aquele que diz branco, mas não entende a mesma coisa com o nome de brancura" (RANCIÈRE, 1996, p. 11). O desentendimento, nesse sentido, não é um mero desconhecimento, tampouco um mal-entendido. Nas palavras do autor: "Os casos de desentendimento são aqueles em que a disputa sobre o que quer dizer falar constitui a própria racionalidade da situação da palavra. Os interlocutores então entendem e não entendem aí a mesma coisa nas mesmas palavras" (RANCIÈRE, 1996, p. 12). Tratam-se de situações de conflito, que podem tomar uma forma litigiosa, a respeito do objeto do diálogo. Isso tanto pode minar a possibilidade diálogo, como pode torná-lo mais fecundo e desafiador.

Ao pensar sobre os desentendimentos em uma política do patrimônio, chamo a atenção para atos que são percebidos como profanações. Esses atos, ao sobreporem usos e significados a bens culturais, podem evocar desentendimentos quanto à "sacralidade" de certos patrimônios, ao passo que, em situações específicas, criam espaços de aparecimento para indivíduos e grupos sociais invisibilizados na cidade. Tais espaços de aparecimento, ainda que insólitos e fugazes, expõem uma esfera pública restritiva ao direito de aparecer, isto é, ao direito de indivíduos e 
grupos de se mostrarem em público do jeito que são ou, ao menos, do jeito que gostariam de serem vistos e reconhecidos.

A profanação do patrimônio cultural é um modo particular de subverter dada "ordem patrimonial”. De acordo com Giorgio Agamben (2007), o profano é o que foi restituído ao uso comum, uso dessacralizante, ainda que atos de profanação possam promover sacralizações de um outro tipo. Frente a ritos de "transubstanciação simbólica", os quais, como apontou Pierre Bourdieu (2004), subtraem determinados bens do livre uso e circulação, a profanação implica subverter uma "ordem patrimonial". Por vezes um ato de profanação, que toma um bem pelo o que ele era antes de ser sacralizado como patrimônio ou pelo o que ele poderia ter se tornado se não tivesse passado por esse tipo de sacralização, implica inverter por completo uma "ordem patrimonial". Nestes casos, há desentendimentos quanto à sacralidade atribuída. Perceber a potência de atos de profanação nos permite deslocar o foco em uma história do patrimônio, ao observar mais de perto as maneiras diversas como indivíduos e grupos se relacionam entre si e com os bens patrimonializados. Ao invés de apenas investir esforços em explicar como políticas públicas afetam a vida social, tomamos um caminho inverso, buscando notar como a vida social afeta as políticas patrimoniais. Em suma, pensar sobre a profanação do patrimônio possibilitanos deslocar nossa atenção dos atos de patrimonialização para perceber, no cotidiano de uma cidade, os usos subversivos do patrimônio cultural.

Duas performances artísticas, realizadas em ocasiões diferentes pelo caminho formado entre as duas fileiras de palmeiras imperiais da Alameda Brüstlein, parodiaram as referências simbólicas do passado da cidade e, de certo modo, profanaram a sacralidade daquele patrimônio cultural. As interpretações de um dos mitos fundadores de Joinville, sua origem vinculada ao dote do casamento do Príncipe de Joinville com a princesa brasileira Francisca Carolina, foram reabertas. Esse mito, apesar da insistência dos historiadores em dizer que os príncipes nunca pisaram nas terras de seu dote matrimonial, e que sequer aventaram a hipótese, permanece inabalável, ao menos entre aqueles que se dizem apaixonados pela história da cidade. Frente a isso, as performances envolveram o patrimônio cultural em novas narrativas sobre o presente e o passado, criando, de modo efêmero, espaços de aparecimento para grupos invisibilizados.

Em 2012, para o evento "artiCIDADE - Espaços de Performação", o ator Robson Benta representou o Príncipe de Joinville ${ }^{10}$. No caminho formado entre as palmeiras, o príncipe surgiu. Entretanto, contrariando qualquer expectativa, na representação teatral era um príncipe negro que chegava para finalmente tomar posse de seu reinado em terras brasileiras. Como informado

${ }^{10}$ O vídeo da performance está disponível online em: <https://vimeo.com/54063601>. Acesso em: 4 jan. 2019. 
no catálogo do evento, o motivo para a performance foi o reconhecimento da presença afrobrasileira em Joinville: "Numa cidade de colonização predominantemente alemã, que esperou por um príncipe que nunca pisou nessas terras, a chegada de um príncipe negro tem a proposta de instigar a reflexão sobre as origens étnicas da população joinvilense” (ILHS, 2012, p. 41). Ao propor reabrir as interpretações do passado local, a performance fez alusão à escravização de africanos no Brasil, lembrando dos negros que habitaram a região da atual cidade de Joinville antes e depois da chegada dos primeiros imigrantes europeus de origem germânica, após 1851 . Como também foi explicado, a performance teve como referência o ato simbólico que ocorreu em 2009 em um antigo cemitério da cidade, o Cemitério do Imigrante. Nesse cemitério, que é patrimônio nacional protegido por tombamento em 1962, estão sepultados alguns imigrantes considerados pioneiros na colonização da cidade. Em 2009, na primeira edição da Semana da Consciência Negra ${ }^{11}$, um ato simbólico lembrou a existência de 14 negros sepultados nesse cemitério: 5 adultos escravizados e 2 libertos, além de 5 crianças filhas de escravizados e 2 filhas de libertos. Como uma lápide a quem nunca teve direito a uma, já que negros e pobres eram sepultados em covas rasas, o ato instituiu um lugar destinado ao ritual em comemoração às memórias da presença negra em Joinville. Anualmente, a homenagem é reencenada no dia 20 de novembro, Dia da Consciência Negra. Em ritual solene, flores brancas são depositadas sobre esse monumento à memória de pessoas negras do passado das quais, além de seus nomes, dos nomes de seus escravizadores e das causas de morte, pouco se sabe (MACHADO, 2018b).

Já em 2015, foi a vez de uma aparição da princesa Francisca Carolina, o que ocorreu durante a realização do I Seminário Inventando Gêneros, evento promovido em Joinville pela Associação Arco-Íris de defesa dos direitos de pessoas LGBT. Em uma tarde de chuva, surgiu às portas do "Palácio dos Príncipes" (sede do Museu Nacional de Imigração e Colonização), uma princesa dublando a cantora Edith Piaf em sua interpretação de La Marseillaise. Porém, tratava-se de uma Drag Queen, ou melhor, uma Drag Princess. A personagem, interpretada por Calupsyta Zabelê, nome artístico de Calu Zabel, subiu pelas escadarias do palácio narrando aos espectadores sua construção enquanto personagem ${ }^{12}$. Na atuação, Calu Zabel chamou a atenção para o fato de que inventar um gênero é ato performativo. Afinal, conforme Judith Butler (2015, p. 252), "a repetição parodística do gênero", a exemplo de uma performance de Drag Queen, denuncia "a ilusão da identidade de gênero como uma profundeza intratável e uma substância

\footnotetext{
${ }^{11}$ A primeira edição da Semana da Consciência Negra de Joinville ocorreu em 2009, no transcurso da semana do dia 20 de novembro, data alusiva ao dia da morte de Zumbi dos Palmares e em que é comemorado, no país, o Dia da Consciência Negra. A organização coube à Prefeitura de Joinville em diálogo com movimentos sociais negros. ${ }^{12} \mathrm{O}$ vídeo da performance está disponível online em: 〈https://vimeo.com/140162647>. Acesso em: 15 out. 2016.
} 
interna". Gênero, conforme a autora, é uma construção sociocultural, é "um 'ato', por assim dizer, que está aberto a cisões, sujeito a paródias de si mesmo, a autocríticas e àquelas exibições hiperbólicas do "natural'” (BULTER, 2015, p. 253). Em Joinville, discussões sobre identidades de gênero de pessoas LGBT foi estimulada por movimentos sociais, como a Associação ArcoÍris, criada em 2008, e pela realização, em 2009 e em 2010, de duas edições de uma Semana da Diversidade. Houve um debate público sobre diversidade sexual. Anteriormente, no dia 17 de maio de 2009, foi realizado um ato simbólico no Dia Internacional de Luta Contra a Homofobia. Uma bandeira arco-íris de 200 metros de comprimento foi estendida por manifestantes ao longo da Alameda Brüstlein. Ao fazer uso desse lugar de visibilidade, buscava-se dar a ver a presença na cidade de pessoas LGBT, assim como suas lutas contra a homofobia, lesbofobia e transfobia.

Nessas paródias dos príncipes de Joinville, o desentendimento evocado não se referia propriamente ao passado da cidade, tampouco aos seus sentidos. As performances não negaram que o casamento dos príncipes selou, em certa medida, o destino da antiga colônia. Também não negaram a força simbólica daquelas personagens na história da cidade, por mais que nunca tenham vivido na antiga Colônia. O desentendimento era em relação ao futuro almejado, pois o passado foi retomado para dar a ver algo ainda por vir: expressaram a vontade de que seja possível conviver bem nas diferenças e de que se possa vislumbrar um possível fim a violências cotidianas contra os que são considerados “diferentes”. Uma utopia? Sem dúvida. Eu apostaria em dizer, contudo, que as performances instituíram no lugar patrimonial "heterotopias", no sentido dado por Michel Foucault (2013). Ao contrário da utopia, que, para o filósofo, "não tem lugar algum", heterotopias são "contestações míticas e reais do espaço em que vivemos", são "espaços absolutamente outros" (FOUCAULT, 2013, p. 20-21). A meu ver, as performances são heterotopias de visibilidade, espaços efêmeros e circunstanciais que criam na cidade uma chance de mostrar diferenças encobertas, uma chance de confrontar a visibilidade do patrimônio para ostentar outras maneiras possíveis de viver. Afinal, para algumas pessoas, como os negros e as pessoas LGBT, aparecer na vida cotidiana já é correr algum risco, inclusive riscos de sofrer violências diversas, não apenas simbólicas. Portanto, o ato de criar em lugares patrimoniais heterotopias indica um desejo de se mostrar livremente aos outros como se é, ou melhor, como se sente que é, sem, com isso, sofrer qualquer tipo de represália. O risco aqui não é apenas o de dialogar com os outros, mas um risco ainda mais difícil, o risco de se mostrar aos outros.

Os espaços outros instituídos nas performances, são, então, "espaços de aparecimento". Judith Butler (2018), ao se valer de um conceito de Hanna Arendt, tem chamado a atenção para a força política do ato de aparecer na vida pública, mesmo que esse aparecimento não implique 
vocalizar uma reivindicação bem definida. São em tais espaços de aparecimento que vislumbro possíveis "lucros" simbólicos ao viver o patrimônio, lucros que excedem a participação cidadã na patrimonialização de bens culturais. Há aqui uma espécie de “economia simbólica informal”. Para Butler (2018, p. 11), mesmo quando se utiliza expressões abrangentes, como, por exemplo, "o povo", a totalização presumida encontra limites, pois há "uma vasta região daqueles que permanecem irreconhecíveis". Uma ação política que diz incluir a "todos", acaba por dar limites a essa totalidade e excluir aqueles que estão de fora, os que são politicamente invisibilizados. Um dos argumentos da autora é o de que "afirmar que um grupo de pessoas continua existindo, ocupando espaço e vivendo obstinadamente já é uma ação expressiva, um evento politicamente significativo, e isso pode acontecer sem palavras". Ainda para ela, “os corpos reunidos 'dizem' não somos descartáveis, mesmo quando permanecem em silêncio" (BULTER, 2018, p. 24). A esfera pública deve ser interpretada, de acordo com a autora, também como esfera da aparência, em que os modos pelos quais podemos aparecer aos outros são regidos por normas restritivas. Portanto, para Butler (2018, p. 44), "é apenas por meio de uma forma insistente de aparecer precisamente quando e onde somos apagados que a esfera da aparência se rompe e se abre de novas maneiras". E isso é sempre muito arriscado. Porém, um tipo de risco que talvez valha a pena e seja importante correr na vida em sociedade.

\section{Considerações finais: a vontade de "descobrir-se" no patrimônio}

Para concluir, retorno à questão colocada anteriormente: Para além de uma participação cidadã relativamente controlada, é possível a qualquer pessoa acumular lucros simbólicos em atos de patrimonialização de bens culturais? Uma resposta a essa questão, ainda que provisória, refere-se às possibilidades de usufruir criativamente do patrimônio cultural como um lugar para “descobrir-se". Essa ação voltada a si próprio, reforçada pelo pronome reflexivo "se", pode ser entendida em um duplo sentido. Por um lado, o sentido mais evidente de "descobrir-se" diz respeito a um desejo, que nos toma a todos com intensidades distintas, de encontrar no mundo que nos cerca algum reflexo da imagem que idealizamos de nós mesmos. Essa busca, que nem sempre é narcisista, tem a ver com a nossa vontade de estabelecer identificações com pessoas e objetos de nosso convívio. Assim, aspiramos encontrar um pouco daquilo que somos em bens culturais patrimonializados na cidade onde vivemos. Por outro lado, a expressão "descobrir-se" diz respeito, em um sentido mais banal, ao desejo de afastar, mesmo que temporariamente, as pressões para que encubramos traços de personalidade e de aparência que poderiam denunciar 
um modo de ser e estar no mundo à margem daquilo que se costuma considerar "normal". Nesse sentido, "descobrir-se" no patrimônio refere-se à busca pelo direito de aparecer na vida pública. Não se trata aqui, propriamente, de estabelecer laços de identificação com o patrimônio, mas, ao contrário, de buscar ganhos simbólicos ao desvelar as alteridades que cindem a vida social.

Entre grupos "irreconhecíveis" em uma cidade, não há, e acredito que nem possa haver, uma "identidade". Eles são muito diferentes entre si. Porém, eles podem exercer alianças na luta pela liberdade de aparecer. Para as pessoas LGBT, ainda que tenham passado pelo ritual de "sair do armário", há sempre um novo armário para se refugiar dos riscos que podem correr na vida com os outros. Por mais que tenha sido "aceita", uma pessoa LGBT constantemente é pressionada para encobrir seus trejeitos que possam denunciar feminilidades ou masculinidades frágeis ou exageradas e, principalmente, para não manifestar afeto por outra pessoa do mesmo sexo em público. As pressões para encobrir-se são o lado perverso de uma suposta "aceitação". Esse tipo de pressão também é corriqueiro a outros indivíduos e grupos. Pessoas negras também são pressionadas a disfarçar seus traços étnicos, tais quais a maneira de mostrar os cabelos, por exemplo. Pessoas negras, em situações particulares, igualmente precisam "sair do armário" para “descobrirem-se” em público como negras. A percepção disso pode dar impulso a alianças entre grupos muito diferentes entre si e com pautas distintas de reivindicação. Há a possibilidade de juntos lutarem pelo direito de todas e de todos de "saírem do armário" para aparecer na vida pública aos outros como bem entendem.

Em momentos excepcionais, como nas performances discutidas no artigo, o patrimônio pode funcionar como um palco iluminado para dar a ver lutas pelo direito de aparecer, ou seja, pelo direito de "descobrir-se". Ao profanar a sacralidade de um patrimônio da cidade, grupos distintos subverteram a "ordem patrimonial" e suscitaram aberturas para outras interpretações sobre o passado e o presente. Isso permitiu buscar visibilidade a formas diferentes de viver o patrimônio, o que deu margem a algum "lucro simbólico" com a patrimonialização, ainda que esse "lucro" possa parecer ínfimo, efêmero e restrito a uma espécie de "economia simbólica informal". Tais atos, ao envolver as pessoas em um tipo de uso do patrimônio que está para além da participação cidadã induzida, não eliminaram a "heterologia" do patrimônio, mas, ao invés, expuseram o artifício heterológico que separa e distancia os cidadãos dos "seus" bens culturais. Buscaram, portanto, estabelecer tão somente uma continuidade indireta entre passado, presente e futuro e uma religação incompleta do extraordinário do patrimônio com o ordinário do cotidiano vividos pelos cidadãos. Por entre as alteridades de uma cidade, alguns atos de 
profanação tentam vislumbrar ganhos simbólicos com a patrimonialização e propor modos mais democráticos de viver o patrimônio e de conviver com os outros no patrimônio.

\section{Referências bibliográficas}

ADELL, Nicolas. Os giros do patrimônio. In: CAVIGNAC, Julie; MACÊDO, Muirakytan K. de (orgs.). Tronco, ramos e raízes!: história e patrimônio cultural do Seridó negro. Natal: EDUFRN, 2016.

APPADURAI, Arjun. Diálogo, Risco e Convivialidade. In: et. al. Podemos viver sem $o$ outro? As posibilidades e os limites da interculturalidade. Lisboa: Tinta da China; Fundação Calouste Gulbenkian, 2009. p. 23-38.

BOURDIEU, Pierre. A produção da crença: contribuições para uma economia dos bens simbólicos. São Paulo: Zouk, 2004.

BUTLER, Judith. Corpos em aliança e a política das ruas: notas para uma teoria performativa de assembleia. Rio de Janeiro: Civilização Brasileira, 2018.

Problemas de Gênero: feminismo e subversão da identidade. Rio de Janeiro: Civilização Brasileira, 2015.

CAMPOS, Yussef Daibert Salomão de. Palanque e patíbulo: o patrimônio cultural na Assembleia Nacional Constituinte (1987-1988). São Paulo: Annablume, 2018.

CARRASCO, Gessonia Leite de Andrade. Entrevista concedida a Diego Finder Machado. Joinville, 2 mar. 2016.

D’ORLÉANS, François Ferdinand Philippe Louis Marie. Diário de um príncipe no Rio de Janeiro. Rio de Janeiro: José Olympio, 2006.

FICKER, Carlos. História de Joinville: crônica da Colônia Dona Francisca. 3. ed. Joinville: Letradágua, 2008. dez. 1961.

La Maison de Joinville: O Palácio dos Príncipes e sua História. A Notícia, Joinville,

FOUCAULT, Michel. A ordem do discurso. São Paulo: Loyola, 1996.

O corpo utópico, as heterotopias. São Paulo: n-1 Edições, 2013.

FUNDAÇÃO CULTURAL DE JOINVILLE (FCJ). Processo de Tombamento Municipal FCJ.CPC.2005-007: Ponte Coberta da Estrada Blumenau. Joinville, FCJ, 2005.

GONÇALVES, José Reginaldo. A retórica da perda: os discursos do patrimônio cultural no Brasil. Rio de Janeiro: UFRJ; IPHAN, 2002.

GUILLAUME, Marc. A política do património. Porto: Campo das Letras, 2003. 
HEINICH, Nathalie. The Making of Cultural Heritage. The Nordic Journal of Aesthetics, Aarhus, p. 119-128, n. 40-41, 2010-2011.

HERKENHOFF, Elly. Era uma vez um simples caminho: fragmentos da história de Joinville. Joinville: Fundação Cultural, 1987.

HORN, Carlos. Tombamento da Rua das Palmeiras. A Notícia, Joinville, 27 abr. 1982, p. 2.

INSTITUTO LUIZ HENRIQUE SCHWANKE (ILHS). Catálogo do artiCIDADE 2012: espaços de performação. Joinville: ILHS, 2012.

JOINVILLE. Decreto $n^{\circ} 12.276$, de 9 de março de 2005. Homologa o tombamento da Alameda Brüstlein, 2005a. Disponível em: <http://leismunicipa.is/ljgrh〉. Acesso em: 4 jan. 2019.

Decreto $\mathrm{n}^{\circ}$ 12.591, de 10 de setembro de 2005. Homologa o tombamento da Ponte Afonso Altrak, 2005b. Disponível em: <http://leismunicipa.is/jircl>. Acesso em: 4 jan. 2019.

Lei $n^{\circ}$ 1.772, de 28 de novembro de 1980. Altera o Art. 17 da Lei $\mathrm{n}^{\circ} 1.514$, de 27 de maio de 1977. Disponível em: 〈http://leismunicipa.is/rfajk〉. Acesso em: 4 jan. 2019.

Lei $n^{\circ} 1.773$, de $1^{\circ}$ de dezembro de 1980. Dispõe sobre a proteção do patrimônio histórico, arqueológico, artístico e natural do município de Joinville. Disponível em: <http://leismunicipa.is/farjk>. Acesso em: 4 jan. 2019.

Lei Complementar $n^{\circ} 363$, de 19 de dezembro de 2011. Institui, no âmbito do município de Joinville, o Inventário do Patrimônio Cultural de Joinville - IPCJ, e dá outras providências. Disponível em: <http://leismunicipa.is/eigkr>. Acesso em: 4 jan. 2019.

MACHADO, Diego Finder Machado. Marcas da Profanação: versões e subversões da ordem patrimonial em Joinville-SC. Tese (Doutorado em História) - Programa de Pós-Graduação em História, Universidade do Estado de Santa Catarina, Florianópolis, 2018a.

Nós difíceis de desatar: reaberturas do passado e sobreposições de narrativas patrimoniais sobre a presença negra em Joinville (SC). Confluências Culturais, Joinville, v. 7, n. 1, p. 21-25, mar. 2018.

MENESES, Ulpiano Toledo Bezerra de. O campo do patrimônio: uma revisão de premissas. In: INSTITUTO DO PATRIMÔNIO HISTÓRICO E ARTÍSTICO NACIONAL (IPHAN). Anais do I Fórum do Patrimônio Cultural. Brasília: IPHAN, 2012. v. 2. t. 1. p. 25-39.

O TOMBAMENTO. A Notícia, Joinville, 12 mai. 1982, p. 2.

PEIXOTO, Paulo. O patrimônio e seus demônios nas sociedades contemporâneas. Boletim Campineiro de Geografia, v. 6, n. 2, p. 289-302, 2016.

POULOT, Dominique. Uma história do patrimônio no Ocidente, séculos XVIII-XXI: do monumento aos valores. São Paulo: Estação Liberdade, 2009.

RADUN, Denis Fernando. $O$ (des)tombamento em questão: (des)patrimonialização de bens culturais tombados pelo órgão federal de preservação no Brasil (1937-2015). Dissertação (Mestrado em Patrimônio Cultural e Sociedade), Programa de Pós-Graduação em Patrimônio Cultural e Sociedade, Universidade da Região de Joinville, Joinville, 2016. 
RANCIÈRE, Jacques. O desentendimento: política e filosofia. São Paulo: Ed. 34, 1996.

ROTHERT, Dietlinde Clara. Entrevista concedida a Bruno da Silva Giane Maria de Souza. Joinville, 3 e 4 mar. 2010.

SANTOS, Mario Ferreira dos. Participação. Tiro de Letra, s/d. Disponível em: <http://www.tirodeletra.com.br/ensaios/Dici-Participacao.htm>. Acesso em: 4 jan. 2019.

SCHNEIDER, Adolfo Bernardo. Parecer sobre o tombamento da Alameda Brüstlein. Coordenação de Patrimônio Cultural, Fundação Cultural de Joinville, Joinville, 11 mai. 1982.

VOGELSANGER, Arinor. Moção $n^{\circ}$ 188, de 21 de setembro de 1993. Câmara dos Vereadores de Joinville, 1993. 